ARTICLE

https://doi.org/10.1038/s41467-019-08631-1

\title{
Direct dehydrogenative alkyl Heck-couplings of vinylarenes with umpolung aldehydes catalyzed by nickel
}

\author{
Leiyang Lv (1) ${ }^{1,2}$, Dianhu Zhu (i) ${ }^{1} \&$ Chao-Jun $\mathrm{Li}^{1}$
}

\begin{abstract}
Alkenes are fundamental functionalities in nature and highly useful intermediates in organic synthesis, medicinal chemistry and material sciences. Transition-metal-catalyzed Heck couplings with organic halides as electrophiles have been established as a powerful protocol for the synthesis of this valuable building block. However, the requirement of organic halides and the generation of stoichiometric hazardous halide wastes may cause significant sustainable concerns. The halide-free oxidative Heck alkenylations involving organometallics or arenes as the coupling partners provide a facile and alternative pathway. Nonetheless, stoichiometric amounts of extra oxidant are essential in most cases. Herein, we present a direct dehydrogenative alkyl Heck-coupling reaction under oxidant-free conditions, liberating hydrogen, nitrogen and water as the side products. Excellent regioselectivity is achieved via neighboring oxygen atom coordination. Broad substrate scope, great functional group (ketone, ester, phenol, free amine, amide etc) tolerance and modification of pharmaceutical candidates and biological molecules exemplified its generality and practicability.
\end{abstract}

\footnotetext{
${ }^{1}$ Department of Chemistry and FRQNT Center for Green Chemistry and Catalysis, McGill University, 801 Sherbrooke Street West, Montreal, Quebec H3A OB8, Canada. ${ }^{2}$ State Key Laboratory of Applied Organic Chemistry, Lanzhou University, 222 Tianshui Road, Lanzhou, Gansu 730000, China. These authors contributed equally: Leiyang Lv, Dianhu Zhu. Correspondence and requests for materials should be addressed to C.-J.L. (email: cj.li@mcgill.ca)
} 
S ince its first discovery in the 1970s, the palladium-catalyzed Heck (or Mizoroki-Heck) reaction has emerged as the most powerful and straightfoward tool for the cross-couplings of alkenes and aryl (pseudo) halides (Fig. 1a) ${ }^{1,2}$. Despite its remarkable importance and widespread applications in organic synthesis $^{3-5}$ over the past decades, this protocol suffers from the inherent disadvantage of the required pre-synthesizing the organic halides and accompanied formation of a stoichiometric amount of hazardous halide salt, which can cause significant environmental concerns. To persuit a more sustainable alkenylation process, the halide-free oxidative Heck coupling reactions via transmetallation or directed $\mathrm{C}-\mathrm{H}$ activation have been developed ${ }^{6-8}$. Organometallic reagents are generally moisture/air sensitive and often not commercially available especially when bearing functional groups (Fig. 1b). Besides, preparation of these reagents requires stoichiometric quantities of metals, thus producing extra metal wastes. Alternatively, the alkenylations through direct cleavage of two $\mathrm{C}-\mathrm{H}$ bonds represent an more environmentally benign and economically attractive strategy (Fig. 1c $)^{9-12}$. As early as in 1967, Fujiwara and Moritani reported the cross-couplings of electron-rich arenes with activated alkenes ${ }^{13}$. Inspired by this precedent work, great achievements have been made in this field ${ }^{14,15}$. However, due to the inherent challenges of selectivity in $\mathrm{C}-\mathrm{H}$ bond activation, the nucleophiles were mostly restricted to the (hetero) arenes with a directing group. Above all, the oxidative Heck reaction generally requires stoichiometric amounts of oxidant (such as metal salt, peroxide, benzoquinone, $\mathrm{K}_{2} \mathrm{~S}_{2} \mathrm{O}_{8}, \mathrm{O}_{2}$, acetone ${ }^{16}$, or internal oxidant ${ }^{17-19}$ etc.) to regenerate the active metal species, thus often affording additional side products. Hence, the development of a dehydrogenative Heck-coupling reaction under oxidant-free conditions is promising and highly desirable ${ }^{20,21}$. In 2016, Jeganmohan and coworkers reported an attractive ruthenium-catalyzed oxidant-free ortho alkenylation of aromatic amides and anilides with acetic acid as an additive ${ }^{22}$. Two examples of electrocatalytic aromatic dehydrogenative Heck coupling of arenes were disclosed by Jutand and Lei groups ${ }^{23,24}$. Recently, Lei and coworkers also realized a direct dehydrogenative $\mathrm{C}-\mathrm{H}$ alkenylation of electronrich arenes with styrene derivatives via a photo-induced electron transfer process ${ }^{25}$.

\section{a Mizoroki-Heck reaction}

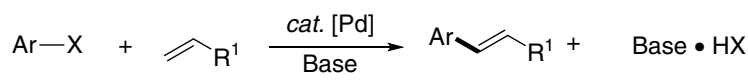

b Alkenylations via transmetallation

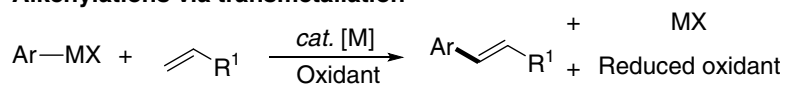

C Alkenylations via $\mathrm{C}-\mathrm{H}$ activation

$$
\begin{aligned}
& \mathrm{R}-\mathrm{H}+\mathrm{R}^{1} \underset{\mathrm{R}=\mathrm{Ar} \text { or Alkyl }}{\stackrel{\text { cat. }[\mathrm{M}]}{\text { Oxidant }}} \stackrel{\mathrm{R}}{\mathrm{R}^{1}}+\text { Reduced oxidant } \\
& \longrightarrow
\end{aligned}
$$

d $\mathrm{H}_{2}$ evolution alkyl nucleophiles (this work)

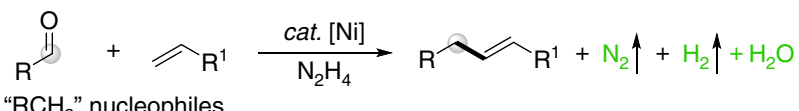

Fig. 1 Strategies in the Heck coupling reaction. a Traditional Mizoroki-Heck coupling with hazardous organic halide; b Oxidative Heck coupling with pre-synthesized organometallic reagent; c Stoichiometric oxidant mediated Heck coupling via $\mathrm{C}-\mathrm{H}$ bond activation; $\mathbf{d}$ Oxidant-free direct dehydrogenative alkyl Heck-coupling
In contrast, alkyl-Heck-type reactions were much more challenging and rarely explored until the last decade. Pioneered by Oshima $^{26}$ and Fu's seminal works ${ }^{27}$, effective strategies have been developed to facilitate this alkenylations with simple alkyl halides as electrophiles ${ }^{28-44}$. Notably, two elegant palladium-catalyzed cases involving alkyl $\mathrm{C}-\mathrm{H}$ activation were disclosed by the groups of $\mathrm{Yu}^{45}$ and Sanford ${ }^{46}$, which employed $N$-arylamide or pyridine as a neighboring directing group with stoichiometric amounts of external oxidant. However, up to now, the oxidant-free, direct generation of $\mathrm{H}_{2}$ from alkyl Heck-type reaction still remains a highly formidable task.

To address these challenges and towards the goal of sustainable transformations, herein, we wish to report the example of direct dehydrogenative alkyl Heck-couplings of vinylarenes with umpolung aldehydes (Fig. 1d). Inspiration of this project stemsfrom our recent studies on hydrazone chemistry, in which umpolung aldehydes act as carbanion equivalents in the catalytic nucleophilic addition ${ }^{47-52}$ and cross-coupling reactions ${ }^{53-56}$. Highlighted features of this strategy are (a) no oxidant needed; (b) $\mathrm{H}_{2}, \mathrm{~N}_{2}$ and $\mathrm{H}_{2} \mathrm{O}$ as innocuous side products; (c) naturally rich aldehydes as environmentally benign alkyl nucleophiles; (d) excellent regioselectivity achieved via vicinal oxygen atom chelation; (e) first-row abundant nickel as catalyst; (f) broad substrate scope and great functional group compatibility; and (g) modification of pharmaceutical candidates and biological molecules.

\section{Results}

Screening of reaction conditions. Our study commenced with a model reaction of styrene (3a) with hydrazone (2a) generated in situ from benzaldehyde (1a) with hydrazine monohydrate (Table 1) [Warning: hydrazine monohydrate is potentially hazardous and should be performed with appropriate personal protection]. We first examined $\mathrm{Ni}(\operatorname{cod})_{2}$ as a catalyst precursor and $N, N$-diisopropyl ethylamine as the base (DIPEA) for the Heck-type reaction. Among the various phosphine ligands evaluated (entries 1-6, see Supplementary Table 1 for details), only the sterically hindered, strong $\sigma$-donor bidentate alkyl phosphine ligand, 1,2-bis(dicyclohexyl phosphanyl)ethane (dcype), favored this transformation, and the product prop-1-ene-1,3-diyldibenzene 4 aa was obtained in $78 \%$ yield with $87: 13 \mathrm{E:Z}$ ratio (entry 6). The liberation of $\mathrm{H}_{2}$ gas was confirmed by gas chromatograph with a TCD detector. The operationally simple Ni(II) precatalysts were then tested (entries 7-10), only $\mathrm{Ni}(\mathrm{acac})_{2}$ afforded the target molecule in $10 \%$ yield. Gratifyingly, $91 \%$ yield of 4 aa was observed with more than 95:5 E:Z selectivity when 0.5 equivalent of $\mathrm{NaI}$ was added (entry 11). Notably, the efficiency of this transformation was almost not affected using twofold excess of benzaldehyde hydrazone 2a (entry 12). Equimolar reaction of styrene $\mathbf{3} \mathbf{a}$ and $\mathbf{2} \mathbf{a}$ still delivered the desired product $\mathbf{4} \mathbf{a a}$ in $58 \%$ yield (entry 14). When the dosage of $\mathrm{Ni}(\operatorname{cod})_{2}$ and dcype was decreased to $5 \mathrm{~mol} \%$, $78 \%$ yield of corresponding 4aa was obtained (entry 15). Control experiments were also carried out to understand the role of each component. It is noteworthy that in absence of base, the reaction efficiency was only decreased slightly (entry 16). This result indicated that base was not essential for this transformation, but might partially assist the initial oxidative addition of nickel complex to $\mathrm{N}-\mathrm{H}$ bond of hydrazone ${ }^{57}$. In absence of either the nickel catalyst or a ligand, the desired product 4aa was not detected (entries 17 and 18).

Scope and limitation of the reaction. With the optimized conditions identified, the substrate scope of olefins 3 was investigated (Fig. 2a). To our delight, an array of mono-substituted vinylarenes containing both electron-donating and electron-withdrawing groups were all proved to be competent substrates, delivering the 


\section{Table 1 Optimization of the reaction conditions}

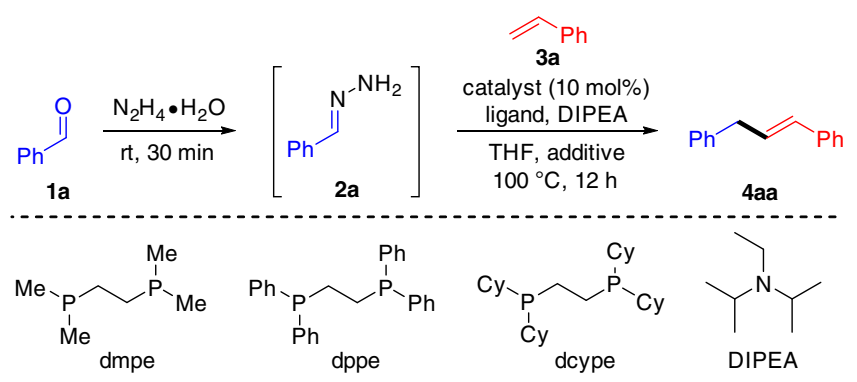

\begin{tabular}{|c|c|c|c|c|}
\hline Entry & Catalyst & Ligand & Additive & $4 a a(\%)^{a, b}$ \\
\hline 1 & $\mathrm{Ni}(\operatorname{cod})_{2}$ & $\mathrm{PMe}_{3}$ & - & N.D. \\
\hline 2 & $\mathrm{Ni}(\mathrm{cod})_{2}$ & $\mathrm{PPh}_{3}$ & - & N.D. \\
\hline 3 & $\mathrm{Ni}(\mathrm{cod})_{2}$ & $\mathrm{PCy}_{3}$ & - & N.D. \\
\hline 4 & $\mathrm{Ni}(\mathrm{cod})_{2}$ & dmpe & - & N.D. \\
\hline 5 & $\mathrm{Ni}(\mathrm{cod})_{2}$ & dppe & - & N.D. \\
\hline 6 & $\mathrm{Ni}(\mathrm{cod})_{2}$ & dcype & - & $78(83: 17)$ \\
\hline 7 & $\mathrm{NiCl}_{2}$ & dcype & - & Trace \\
\hline 8 & $\mathrm{NiBr}_{2}$ & dcype & - & Trace \\
\hline 9 & $\mathrm{NiBr}_{2} \cdot$ glyme & dcype & - & Trace \\
\hline 10 & $\mathrm{Ni}(\mathrm{acac})_{2}$ & dcype & - & $10(78: 22)$ \\
\hline 11 & $\mathrm{Ni}(\mathrm{cod})_{2}$ & dcype & $\mathrm{Nal}$ & $91(87)^{C}(>95: 5)$ \\
\hline $12^{d}$ & $\mathrm{Ni}(\operatorname{cod})_{2}$ & dcype & $\mathrm{Nal}$ & $85(>95: 5)$ \\
\hline $13^{e}$ & $\mathrm{Ni}(\mathrm{cod})_{2}$ & dcype & $\mathrm{Nal}$ & $71(>95: 5)$ \\
\hline $14^{f}$ & $\mathrm{Ni}(\mathrm{cod})_{2}$ & dcype & $\mathrm{Nal}$ & $58(>95: 5)$ \\
\hline $15 g$ & $\mathrm{Ni}(\mathrm{cod})_{2}$ & dcype & $\mathrm{Nal}$ & $78(>95: 5)$ \\
\hline $16^{\mathrm{h}}$ & $\mathrm{Ni}(\mathrm{cod})_{2}$ & dcype & $\mathrm{Nal}$ & $69(>95: 5)$ \\
\hline 17 & $\mathrm{Ni}(\operatorname{cod})_{2}$ & - & $\mathrm{Nal}$ & N.D. \\
\hline 18 & - & dcype & $\mathrm{Nal}$ & N.D. \\
\hline
\end{tabular}

Reaction conditions: $\left.\mathbf{3 a}(0.2 \mathrm{mmol}), \mathbf{1 a}(0.6 \mathrm{mmol}), \mathrm{N}_{2} \mathrm{H}_{4} \cdot \mathrm{H}_{2} \mathrm{O}(0.72 \mathrm{mmol}), \mathrm{Ni}(\mathrm{cod})\right)_{2}(10 \mathrm{~mol} \%)$, ligand $(20 \mathrm{~mol} \%$ for monodentate, $10 \mathrm{~mol} \%$ for bidentate), DIPEA (0.4 mmol), $\mathrm{Nal}(0.1 \mathrm{mmol}), \mathrm{THF}$ $(1.0 \mathrm{~mL}), 100^{\circ} \mathrm{C}, 12 \mathrm{~h}$ under $\mathrm{N}_{2}$ unless otherwise noted

N.D. not detected

aNMR yields were determined by ${ }^{1} \mathrm{H}$ NMR using mesitylene as an internal standard and based on $\mathbf{3 a}$

bThe $E: Z$ ratio in parenthesis was determined by ${ }^{1} \mathrm{H}$ NMR analysis of the crude mixture

The isolated yield in parenthesis

1a $(0.4 \mathrm{mmol}), \mathrm{N}_{2} \mathrm{H}_{4} \cdot \mathrm{H}_{2} \mathrm{O}(0.48 \mathrm{mmol})$ instead

1a $(0.3 \mathrm{mmol}), \mathrm{N}_{2} \mathrm{H}_{4} \cdot \mathrm{H}_{2} \mathrm{O}(0.36 \mathrm{mmol})$ instead

a $(0.2 \mathrm{mmol}), \mathrm{N}_{2} \mathrm{H}_{4} \cdot \mathrm{H}_{2} \mathrm{O}(0.24 \mathrm{mmol})$ instead

$\mathrm{g} \mathrm{Ni}(\mathrm{cod})_{2}(5 \mathrm{~mol} \%)$, ligand $(5 \mathrm{~mol} \%)$ instead

hWithout adding DIPEA

desired products $4 \mathbf{a b}-\mathbf{a o}$ in $64-96 \%$ yields. The allylic isomerization of the product was attributed to the presence of $\mathrm{Ni}-\mathrm{H}$ species in the reaction process. Trace amount of hydrogenation product of styrene was also detected by GC-MS. Various functional groups, including methyl (4ab-ad), tert-butyl (4ae), phenyl (4af), methoxyl (4ag-ah), fluoride (4ai), and trifluoromethyl (4aj), were accommodated under the optimal conditions. Remarkably, the alkenes with sensitive functional groups such as hydroxyl (4ak), ester (4al), amine (4am), and amide (4an), which are typically biased in the presence of organometallic reagents, could efficiently participated in this reaction. Steric hindrance on the double bond of vinylarene diminished the yield. For example, the target product 4ap was obtained in 38\% yield when 1,1-diphenylethylene was applied. Treatment of $\alpha$-methylstyrene under the standard conditions gave the allylic isomers 4aq and 4aq' in combined $64 \%$ yield with 60:40 regioselectivity. With respect to $\beta$-methylstyrene, Z:E isomers (4ar and 4ar') were achieved in combined $35 \%$ yield. Unfortunately, vinylsilane, aliphatic and electron-deficient alkenes failed to give the corresponding products under the current catalytic system.

Next, we proceeded to examine the substrate scope of aldehydes 1 (Fig. 2b). In general, the electronic effects of the nucleophiles did not influence the efficiency of this transformation. Aldehydes bearing both electron-donating and electron- withdrawing substituents all reacted smoothly with styrene 3a to afford the products $\mathbf{4 b a - b m}$ in $65-94 \%$ yields. Hetero-aromatic aldehydes, such as furan-2-carbaldehyde and thiophene-3carbaldehyde, also successfully gave the desired products (4bn and $\mathbf{4 b o}$ ) in moderate yields. To our delight, aliphatic aldehydes, such as propionaldehyde and iso-butyraldehyde, which are challenging substrates in the previous reports, were also applicable in this Heck-type reaction (4bp and $4 \mathbf{b q}$ ). Moreover, the attempt to apply ketone as a nucleophile in this transformation also proved feasible (4br).

It is worth noting that an excellent regioselectivity (>95:5) was observed when furan-2-carbaldehyde 1n was examined (Fig. 2b, 4bn). We therefore hypothesized that if the chelation or directing effect of the vicinal oxygen atom inhibited the allylic isomerization $^{58}$. Thus, the phenyl aldehyde with an ortho-methoxyl group $1 s$ was selected as the electrophile candidate. As shown in Fig. 2c, a variety of vinylarenes attached with different functional groups were re-examined with 2-methoxybenzaldehyde 1 s under the optimal conditions, and excellent regioselectivity (mostly >95:5) of the desired products $\mathbf{4} \mathbf{c a}-\mathbf{c m}$ were obtained also with good yields. Furthermore, the olefins bearing heterocyclic skeletons including pyridine, dibenzo-furan, functionalized indole and carbazole, were all viable substrates, affording the corresponding products $(4 \mathrm{cn}-\mathrm{cs})$ in $68-92 \%$ yields. 


$$
\begin{aligned}
& \widehat{A_{3}{ }^{2}}
\end{aligned}
$$

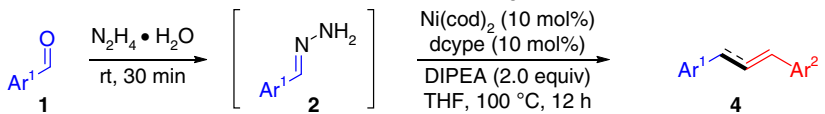

\section{a Scope of vinylarenes}<smiles>Cc1ccc(/C=C/Cc2ccccc2)cc1</smiles>

4ab, $89 \%(76: 24)$<smiles>Cc1cccc(/C=C/Cc2ccccc2)c1</smiles>

$4 a c, 85 \%(79: 21)$<smiles>COc1ccc(/C=C/Cc2ccccc2)cc1OC</smiles>

4ah, $87 \%(74: 26)$<smiles>NC(=O)Nc1ccc(/C=C/Cc2ccccc2)cc1</smiles>

4an, 93\% (79:21)<smiles>Fc1ccc(/C=C/Cc2ccccc2)cc1</smiles>

4ai, $96 \%(62: 38)$

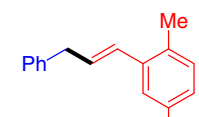

4ad, $88 \%(57: 43) \mathrm{Me}$<smiles>FC(F)(F)c1ccc(/C=C/Cc2ccccc2)cc1</smiles>

4aj, $79 \%(62: 38)$<smiles>CC(C)(C)c1ccc(/C=C/Cc2ccccc2)cc1</smiles>

4ae, $89 \%(76: 24)$<smiles>C(=C/c1ccc(-c2ccccc2)cc1)\c1ccccc1</smiles>

4af, $81 \%(81: 19)$<smiles>COc1ccc(/C=C/Cc2ccccc2)cc1</smiles>

4ag, $86 \%(75: 25)$<smiles>CC(=O)Oc1ccc(/C=C/Cc2ccccc2)cc1</smiles>

4al, $64 \%(76: 24)$<smiles>Nc1ccc(/C=C/Cc2ccccc2)cc1</smiles>

4am, 74\% (94:6)

$$
\text { 4ap, } 38 \%
$$

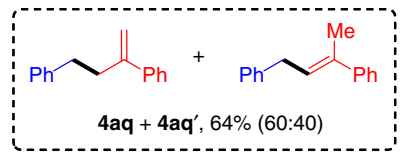

b scope of aldehydes<smiles>Cc1ccc(C/C=C/c2ccccc2)cc1</smiles>

4ba, $92 \%(72: 28)$<smiles>Cc1ccccc1CC=Cc1ccccc1</smiles>

4bb, $89 \%(76: 24)$<smiles>Cc1cccc(C/C=C/c2ccccc2)c1</smiles>

4bc, $94 \%(68: 32)$<smiles>Cc1ccc(C/C=C/c2ccccc2)c(C)c1</smiles>

4bd, $88 \%$ (73:27)<smiles>C(=C/c1ccccc1)\Cc1ccc2c(c1)CCC2</smiles>

4be, $86 \%$ (71:29)<smiles>COc1ccc(C=Cc2ccccc2)cc1</smiles>

4bf, $82 \%(72: 28)$<smiles>COc1cccc(C/C=C/c2ccccc2)c1</smiles>

4bg, $81 \%(71: 29)$

4bh, $72 \%(71: 29)$<smiles>COc1cc(C/C=C/c2ccccc2)cc(OC)c1OC</smiles>

4bi, $78 \%(71: 29)$<smiles>Fc1ccccc1CC=Cc1ccccc1</smiles>

4bj, 93\% (87:13)<smiles>Fc1ccc(C/C=C/c2ccccc2)cc1</smiles>

4bk, 93\% (87:13)

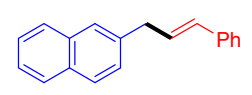

4bl, 76\% (76:24)

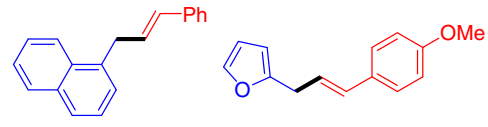

4bm, 65\% (72:28)

4bn, $42 \%$ (> 95:5)

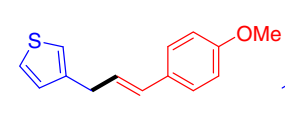

4bo, $38 \%$ (40:60)

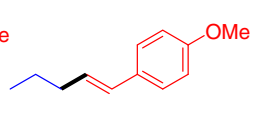

4bp, $42 \%(E: Z>94: 6)$

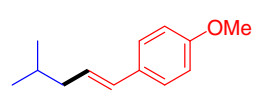

4bq, $39 \%(E: Z>95: 5)$

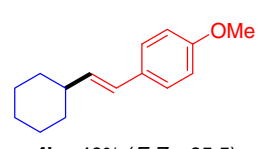

4br, $40 \%(E: Z>95: 5)$

C Regioselective synthesis

$$
{ }_{\mathrm{OMe}}^{\mathrm{Ph}}
$$

4ca, 92\% (> 95:5)<smiles>COc1ccccc1C/C=C/c1ccc(OC)c(OC)c1</smiles>

4cf, $91 \%$ (> 95:5)<smiles>COc1ccccc1C/C=C/c1ccc(O)cc1</smiles>

4ck, $65 \%$ (> 95:5)

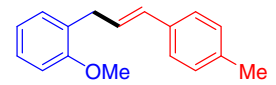

4cb, $85 \%$ (> 95:5) 4cg, $87 \%$ (> 95.5)

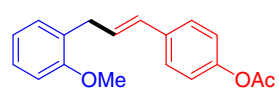

4cl, 55\% (> 94:6)

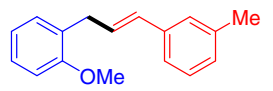

4cc, $76 \%$ (> 95:5)

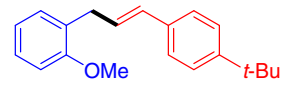

4cd, $83 \%$ (> 94:6)

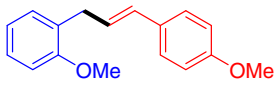

4ce, $82 \%$ (>95:5)<smiles>COc1ccccc1CC=Cc1ccc(-c2ccccc2)cc1</smiles>

4ch, $82 \%$ (> 95:5)

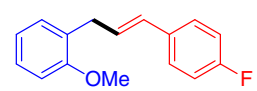

4ci, $81 \%(>91: 9)$

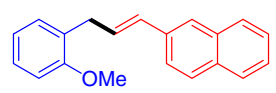

4cm, 75\% (> 95:5)

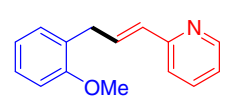

4cn, 83\% (> 91:9)

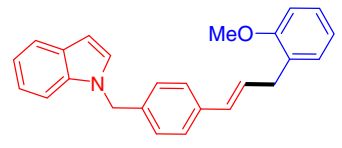

4cp, $81 \%$ (> 81:19)

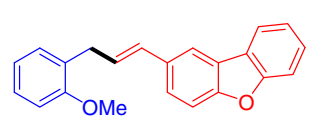

4cq, $92 \%$ (> 91:9)

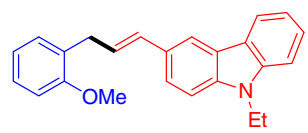

4cr, $68 \%(>97: 3)$<smiles>COc1ccccc1CC=Cc1ccc(N)cc1</smiles>

4cj, $77 \%$ (> 94:6)<smiles>COc1ccccc1CC=Cc1ccc2c(c1)CCN2C</smiles>

4co, $71 \%(>94: 6)$

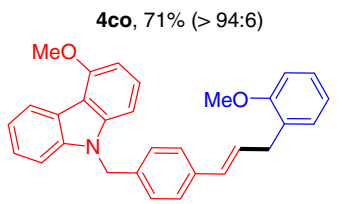

4cs, $88 \%$ (> $89: 11)$

Fig. 2 Scope of substrates. Reaction conditions: $3(0.2 \mathrm{mmol}), \mathbf{1}(0.6 \mathrm{mmol}), \mathrm{N}_{2} \mathrm{H}_{4} \cdot \mathrm{H}_{2} \mathrm{O}(0.72 \mathrm{mmol}), \mathrm{Ni}(\mathrm{cod}) 2(10 \mathrm{~mol} \%)$, dcype (10 mol\%), DIPEA $(0.4 \mathrm{mmol}), \mathrm{Nal}(0.1 \mathrm{mmol})$, THF $(1.0 \mathrm{~mL}), 100^{\circ} \mathrm{C}, 12 \mathrm{~h}$ under $\mathrm{N}_{2}$. Reported yields are the isolated ones (the ratio of allylic isomerization was in parentheses), the $E: Z$ ratio was more than 20:1 unless otherwise noted. ${ }^{a}$ The Z:E ratio in parenthesis 
a

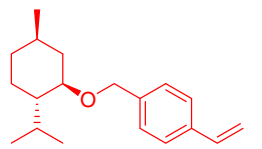

5, from L-menthol derivative

b

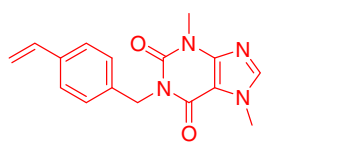

7, from theobromine derivative<smiles>C=Cc1ccc(Cn2cnc3c2c(=O)n(C)c(=O)n3C)cc1</smiles>

9, from theophylline derivative

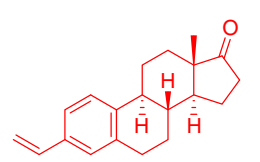

11 , from estrone derivative<smiles>C=Cc1ccc(COc2ccc3c(c2)CC[C@@H]2[C@H]3CC[C@]3(C)C(=O)CC[C@H]23)cc1</smiles>

13, from estrone derivative

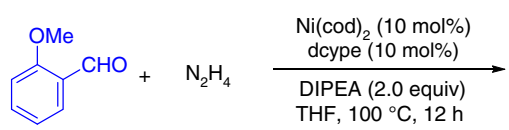

$$
2 \mathrm{CHO}+\mathrm{N}_{2} \mathrm{H}_{4} \frac{\begin{array}{l}
\mathrm{Ni}(\mathrm{cod}))_{2}(10 \mathrm{~mol} \%) \\
\text { dcype }(10 \mathrm{~mol} \%)
\end{array}}{\begin{array}{l}
\mathrm{DIPEA}(2.0 \text { equiv) } \\
\mathrm{THF}, 100^{\circ} \mathrm{C}, 12 \mathrm{~h}
\end{array}}
$$
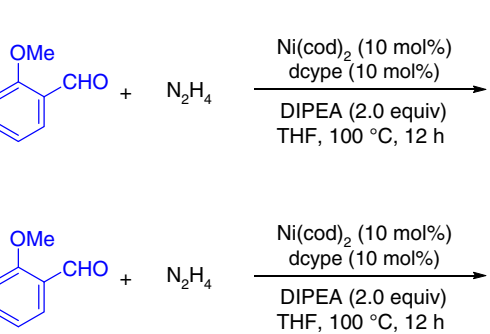

$\mathrm{Ni}(\mathrm{cod})_{2}(10 \mathrm{~mol} \%)$

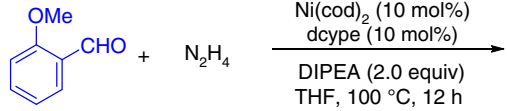

THF, $100^{\circ} \mathrm{C}, 12 \mathrm{~h}$

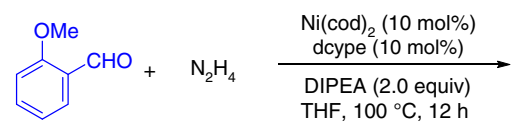

THF, $100^{\circ} \mathrm{C}, 12 \mathrm{~h}$

15 , from tyrosine derivative<smiles>CCc1ccc(COc2c(C)c(C)c3c(c2C)CCC(CCCC(C)NCC(C)C)O3)cc1</smiles>

17 , from $\alpha$-tocopherol derivative

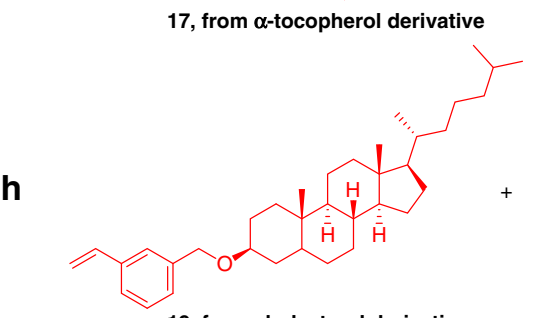

19 , from cholesterol derivative THF, $100^{\circ} \mathrm{C}, 12 \mathrm{~h}$
$\mathrm{THF}, 100^{\circ} \mathrm{C}, 12 \mathrm{~h}$

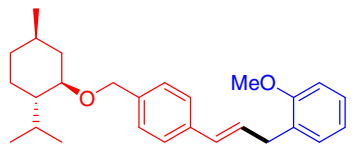

6, $79 \%(>94: 6)$
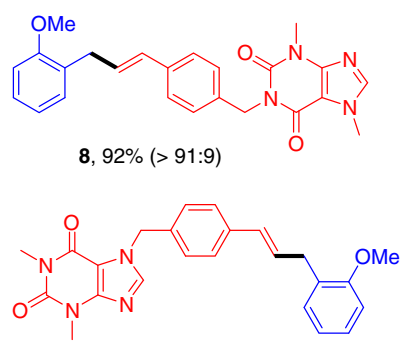

$10,88 \%(>87: 13)$
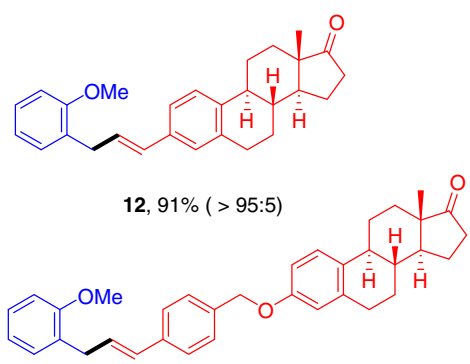

$14,76 \%(>95: 5)$<smiles>CCOC(=O)C(Cc1ccc(OCc2ccc(/C=C/Cc3ccccc3OC)cc2)cc1)NC(C)=O</smiles>

$16,62 \%(>97: 3)$<smiles>COc1ccccc1C/C=C/c1ccc(COc2c(C)c(C)c3c(c2C)CCC(C)(CCCC(C)NC(C)C(C)C)O3)cc1</smiles>

18, $83 \%(>94: 6)$

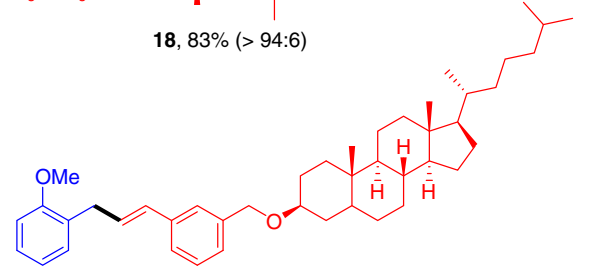

$20,85 \%(>94: 6)$

Fig. 3 Functionalization of naturally and pharmaceutically important derivatives. a Regioselective Heck coupling of L-Menthol derivative; b Regioselective Heck coupling of Theobromine derivative; c Regioselective Heck coupling of Theophylline derivative; d Regioselective Heck coupling of vinyl Estrone derivative; e Regioselective Heck coupling of Estrone derivative; $\mathbf{f}$ Regioselective Heck coupling of Tyrosine derivative; $\mathbf{g}$ Regioselective Heck coupling of $\alpha$-Tocopherol derivative; $\mathbf{h}$ Regioselective Heck coupling of Cholesterol derivative

Synthetic applications. The promising functional group tolerance and high-efficiency of this protocol enabled its application to the modification of pharmaceuticals and natural product derivatives (Fig. 3). For example, introducing ortho-methoxyl benzyl group into L-Menthol (5) was successfully achieved in excellent yield with good regioselectivity (>94:6). Alkaloids such as Theobromine (7) and Theophylline derivatives (9) reacted smoothly under current catalytic system. The estrone derivatives 11 and $\mathbf{1 3}$ were also tested as superior candidates, delivering the target molecules $\mathbf{1 2}$ and $\mathbf{1 4}$ with the ketone moiety untouched. In addition, the structural elaboration of tyrosine derivative (15) was readily accomplished with this nickel-catalyzed oxidant-free Heck-coupling strategy.
Moreover, the cross-couplings of $1 \mathrm{~s}$ with $\alpha$-Tocopherol and Cholesterol derivatives were investigated under the optimized conditions, and the expected benzylation products (18 and 20) were all obtained in good yields $(>80 \%)$. These examples highlighted the wide applicablity and compatiblity of the method, and its enrichment of the tool box for the modification of complex bioactive molecules.

Mechanistic investigation. To gain preliminary insights into the reaction mechanism, several control experiments were subsequently carried out. Firstly, the reaction of styrene (3a) with phenyldiazomethane (21) did not afford the desired 
(E)-prop-1-ene-1,3-diyldibenzene (4aa) (Fig. 4a). When 1,2diphenylcyclopropane (22) was applied under the standard conditions, the desired product 4aa was also not observed (Fig. 4b). a

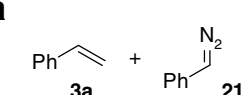

b

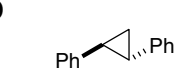

22, trans: cis $=4.3: 1$ Recovered quantitatively

C<smiles>COc1ccc(CCCc2ccccc2)cc1</smiles>

Recovered quantitatively

d $\overbrace{3 a}^{\curvearrowright}+\overbrace{2 a}^{\mathrm{Ph}^{-\mathrm{NH}_{2}}} \quad \begin{gathered}\begin{array}{c}\text { Standard } \\ \text { conditions }\end{array} \\ \mathrm{BHT}(0.5 \text { equiv) }\end{gathered}$

f

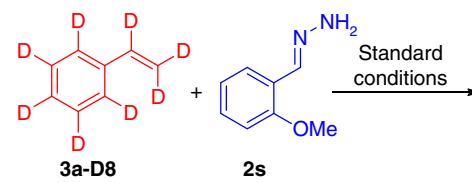

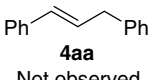

Not observed

4aa

Not observed

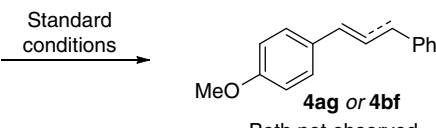

Both not observed

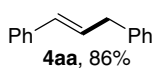

$$
\text { Not observed }
$$
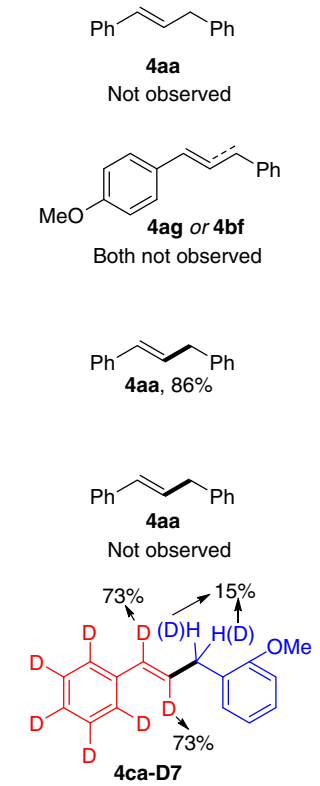

Fig. 4 Mechanistic studies. a Reaction of styrene with phenyldiazomethane did not give the desired product; $\mathbf{b}$ Reaction of 1,2-diphenylcyclopropane under the standard conditions did not give the desired product; c Reaction of 1-methoxy-4-(3-phenylpropyl)benzene under the standard conditions did not give the desired product; d Radical scavenger, 2,6-di-tert-butyl-4methylphenol (BHT) added and the reaction was almost unaffected; e $N$-Ts hydrazone used instead of simple hydrazone did not give the desired product; $\mathbf{f} / \mathrm{D}$ exchanges occurred in the isotope experiment
These two results ruled out the possibility that hydrazone played the role of carbene precursor or diazo species to undergo cyclopropanation and subsequent ring opening during the reaction course ${ }^{59}$. Secondly, when 1-methoxy-4-(3-phenylpropyl)benzene (23) was tested, neither $4 \mathbf{a g}$ nor its regioisomer $\mathbf{4 b f}$ was detected (Fig. 4c). This observation suggested the unlikely involvement of hydrazone addition to the vinylarene followed by dehydrogenation pathway. Thirdly, the efficiency of the model reaction was almost unaffected in the presence of a radical scavenger, 2,6di-tert-butyl-4-methylphenol (BHT), indicating the unlikelihood of a radical mechanism in the current reaction (Fig. 4d). When $\mathrm{N}$-Ts hydrazone $\mathbf{2 4}$ was used in the place of simple hydrazone 1a, no desired product 4 aa was observed, which accounted for the totally diverse characters between the two different types of

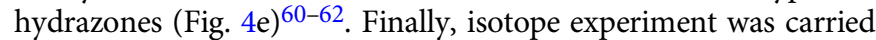
out (Fig. 4f). H/D exchanges both in the double bond moiety $(73 \% \mathrm{D})$ and benzylic position $(15 \% \mathrm{D})$ revealed that iterative $\mathrm{Ni}-(\mathrm{H}) \mathrm{D}$ species addition/elimination steps existed during the reaction process ${ }^{63,64}$.

Although, the exact mechanism still remained unclear at this moment, on the basis of literature reports ${ }^{6,47-56}$ and our findings, a plausible reaction pathway was proposed in Fig. 5. Initially, the active nickel(0) species, which potentially complexed to the olefin, coordinated with hydrazone to form a six-membered intermediate $\mathbf{B}$. Then the nickel catalyst undergoes oxidative addition to the $\mathrm{N}-\mathrm{H}$ bond likely with the assistance of DIPEA and delivers the key intermediate C. A similar $\mathrm{N}-\mathrm{H}$ bond activation of simple hydrazone was also observed with a manganese pincer complex by Milstein and coworkers $^{57}$. At this stage, intramolecular regioselective 1,2insertion occurs to afford the complex $\mathbf{D}$, which then undergoes concerted $\beta$-hydride elimination and releases $\mathrm{N}_{2}$ gas (WolffKishner reductive denitrogenation) to deliver the desired product 4 and $\mathrm{Ni}-\mathrm{H}$ species $\mathbf{E}$. This metal-hydride releases $\mathrm{H}_{2}$ gas and regenerates the active $\mathrm{Ni}(0)$ catalyst to close the catalytic cycle. $\mathrm{NaI}$ as the additive enhances both the reactivity and E:Z selectivity, possibly through halide effects that assist the decomposition of intermediate $\mathbf{D}$ to produce thermodynamically more favored trans-alkene ${ }^{65}$. The allylic isomerization was due to the iterative $\mathrm{Ni}-\mathrm{H}$ addition/ elimination.

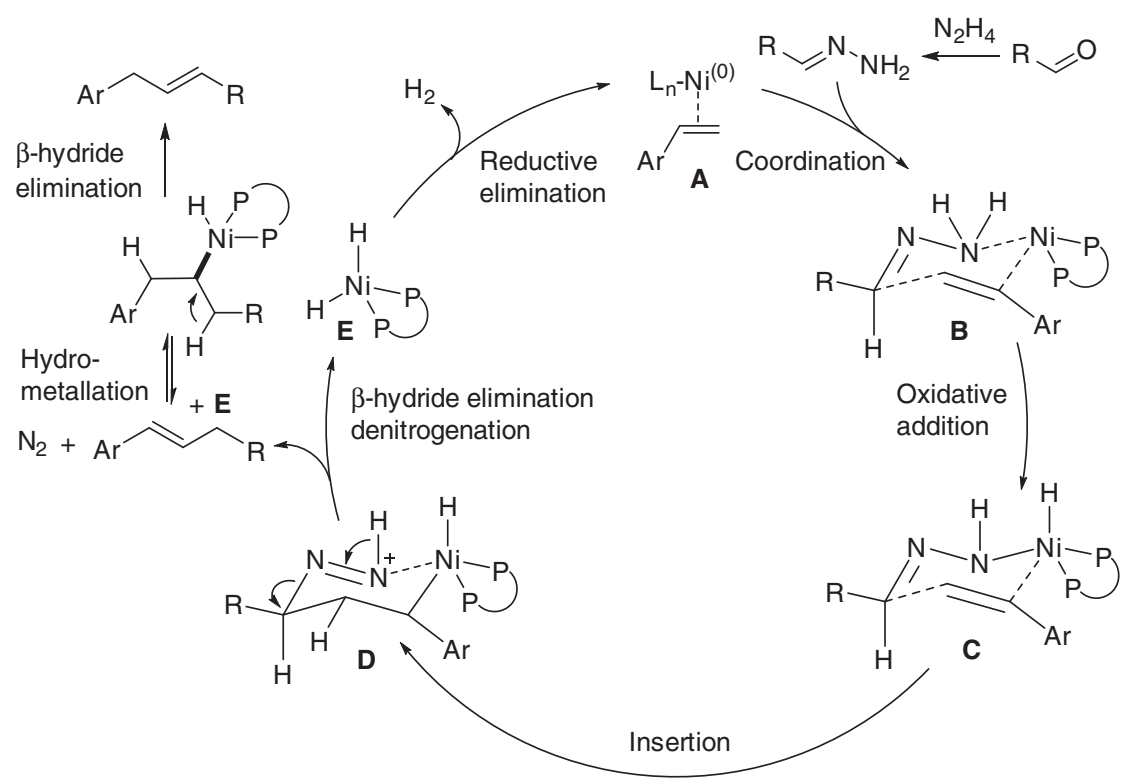

Fig. 5 Reaction mechanism. Proposed pathway for the oxidant-free Heck-type reaction 


\section{Discussion}

In summary, we have documented an efficient protocol for alkyl Heck-type reaction of vinylarenes with umpolung aldehydes under a simple nickel catalyst system. This strategy proceeds smoothly in absence of halides, organometallics or oxidant, liberating hydrogen, nitrogen, and water as innocuous side products. Excellent regioselectivity was achieved with the assistance of heteroatom chelation effect. Broad substrate scope, great functional group compatibility and modification of complex organic molecules containing olefin moieties made this methodology synthetically useful and valuable. Preliminary mechanistic studies revealed that the transformation did not proceed through carbene insertion, cyclopropane opening, nucleophilic addition/dehydrogenation or radical process. Detailed studies aimed at elucidating the mechanism and further applications of aldehydes as alkyl nucleophiles in chemical transformations are ongoing in our lab.

\section{Methods}

In situ preparation of hydrazone solution. A mixture of aldehydes $1(0.6 \mathrm{mmol}$, 3.0 equiv) and hydrazine monohydrate ( $36 \mu \mathrm{L}, 0.72 \mathrm{mmol}, 64-65 \mathrm{wt} \%, 3.6$ equiv) in THF $(0.6 \mathrm{~mL})$ solution was stirred for $30 \mathrm{~min}$ at room temperature in air. Before use, a small amount of anhydrous $\mathrm{Na}_{2} \mathrm{SO}_{4}$ and $4 \AA$ MS was added.

General procedure for dehydrogenative alkyl Heck-couplings. In a glovebox, a flame-dried reaction tube $\left(10 \mathrm{~cm}^{3}\right)$ equipped with a magnetic stir bar was charged with $\mathrm{Ni}(\mathrm{cod})_{2}(5.6 \mathrm{mg}, 10 \mathrm{~mol} \%)$, dcype $(8.5 \mathrm{mg}, 10 \mathrm{~mol} \%)$ and THF $(0.4 \mathrm{~mL})$ before being sealed with a rubber septum. The reaction mixture was stirred at room temperature for $30 \mathrm{~min}$. Then vinylarene $\mathbf{3}(0.2 \mathrm{mmol}, 1.0$ equiv), hydrazone solution $2(0.6 \mathrm{mmol}$ in $0.6 \mathrm{~mL}$ THF), DIPEA $(0.4 \mathrm{mmol}, 67 \mu \mathrm{L})$ and $\mathrm{NaI}(0.1 \mathrm{mmol}, 15 \mathrm{mg})$ were added sequentially. After that, the reaction mixture was sealed with aluminum cap, moved out of glovebox and stirred at $100^{\circ} \mathrm{C}$ for $12 \mathrm{~h}$. After the mixture was cooled to rt, the resulting solution was directly filtered through a pad of silica by EtOAc $(3.0 \mathrm{~mL})$. The crude mixture was analyzed by GCMS. The solvent was evaporated in vacuo to give the crude products. NMR yields were determined by ${ }^{1} \mathrm{H}$ NMR using mesitylene as an internal standard. The residue was purified by preparative TLC (ethyl acetate/hexane) to give the pure product 4 .

Notes. Use of the glovebox is not necessary unless to store and manipulate airsensitive $\mathrm{Ni}(\operatorname{cod})_{2}$ catalyst. The other operations can be successfully performed outside the glovebox with standard Schlenk line procedure. One pot reaction of vinylarenes, aldehydes and hydrazine without preparation of hydrazones beforehand afforded only trace amount of desired products.

\section{Data availability}

The authors declare that the data supporting the findings of this study are available within the article and Supplementary Information file, or from the corresponding author upon reasonable request.

Received: 11 October 2018 Accepted: 20 January 2019

Published online: 12 February 2019

\section{References}

1. Tsutomu, M., Kunio, M. \& Atsumu, O. Arylation of olefin with aryl iodide catalyzed by palladium. Bull. Chem. Soc. Jpn. 44, 581-581 (1971).

2. Heck, R. F. \& Nolley, J. P. Palladium-catalyzed vinylic hydrogen substitution reactions with aryl, benzyl, and styryl halides. J. Org. Chem. 37, 2320-2322 (1972).

3. Beletskaya, I. P. \& Cheprakov, A. V. The Heck reaction as a sharpening stone of palladium catalysis. Chem. Rev. 100, 3009-3066 (2000).

4. Dounay, A. B. \& Overman, L. E. The asymmetric intramolecular Heck reaction in natural product total synthesis. Chem. Rev. 103, 2945-2964 (2003).

5. Oestreich, M. The Mizoroki-Heck Reaction. (Wiley \& Sons, Chichester, 2009).

6. Le Bras, J. \& Muzart, J. Intermolecular dehydrogenative Heck reactions. Chem. Rev. 111, 1170-1214 (2011)

7. Yeung, C. S. \& Dong, V. M. Catalytic dehydrogenative cross-coupling: forming carbon-carbon bonds by oxidizing two carbon-hydrogen bonds. Chem. Rev. 111, 1215-1292 (2011).

8. Ferreira, E. M., Zhang, H. \& Stoltz, B. M. Oxidative Heck-Type Reactions, vol. 9 (ed Oestreich, M.) 345-382 (Wiley-VCH, Weinheim, 2009).
9. Tang, S., Liu, K., Liu, C. \& Lei, A. Olefinic C-H functionalization through radical alkenylation. Chem. Soc. Rev. 44, 1070-1082 (2015).

10. Werner, E. W., Mei, T.-S., Burckle, A. J. \& Sigman, M. S. Enantioselective Heck arylations of acyclic alkenyl alcohols using a redox-relay strategy. Science 338, 1455-1458 (2012).

11. Kozhushkov, S. I. \& Ackermann, L. Ruthenium-catalyzed direct oxidative alkenylation of arenes through twofold $\mathrm{C}-\mathrm{H}$ bond functionalization. Chem. Sci. 4, 886-896 (2013).

12. Li, C.-J. Cross-Dehydrogenative Coupling (CDC): exploring C-C bond formations beyond functional group transformations. Acc. Chem. Res. 42, 335-344 (2009).

13. Moritani, I. \& Fujiwara, Y. Aromatic substitution of styrene-palladium chloride complex. Tetrahedron Lett. 8, 1119-1122 (1967).

14. Jia, C., Kitamura, T. \& Fujiwara, Y. Catalytic functionalization of arenes and alkanes via C-H bond activation. Acc. Chem. Res. 34, 633-639 (2001).

15. Jia, C. et al. Efficient activation of aromatic $\mathrm{C}-\mathrm{H}$ bonds for addition to $\mathrm{C}-\mathrm{C}$ multiple bonds. Science 287, 1992-1995 (2000).

16. Ruan, J., Li, X., Saidi, O. \& Xiao, J. Oxygen and base-free oxidative Heck reactions of arylboronic acids with olefins. J. Am. Chem. Soc. 130, 2424-2425 (2008).

17. Wu, J., Cui, X., Chen, L., Jiang, G. \& Wu, Y. Palladium-catalyzed alkenylation of quinoline- $\mathrm{N}$-oxides via $\mathrm{C}$ - $\mathrm{H}$ activation under external-oxidant-free conditions. J. Am. Chem. Soc. 131, 13888-13889 (2009).

18. Guimond, N., Gorelsky, S. I. \& Fagnou, K. Rhodium(III)-catalyzed heterocycle synthesis using an internal oxidant: improved reactivity and mechanistic studies. J. Am. Chem. Soc. 133, 6449-6457 (2011).

19. Rakshit, S., Grohmann, C., Besset, T. \& Glorius, F. Rh(III)-catalyzed directed C-H olefination using an oxidizing directing group: mild, efficient, and versatile. J. Am. Chem. Soc. 133, 2350-2353 (2011).

20. Liu, C., Zhang, H., Shi, W. \& Lei, A. Bond formations between two nucleophiles: transition metal catalyzed oxidative cross-coupling reactions. Chem. Rev. 111, 1780-1824 (2011).

21. Liu, C. et al. Oxidative coupling between two hydrocarbons: an update of recent C-H functionalizations. Chem. Rev. 115, 12138-12204 (2015).

22. Manikandan, R., Madasamy, P. \& Jeganmohan, M. Ruthenium-catalyzed ortho alkenylation of aromatics with alkenes at room temperature with hydrogen evolution. ACS. Catalysis 6, 230-234 (2016).

23. Amatore, C., Cammoun, C. \& Jutand, A. Electrochemical recycling of benzoquinone in the Pd/benzoquinone-catalyzed Heck-type reactions from arenes. Adv. Synth. Catal. 349, 292-296 (2007).

24. Tang, S., Gao, X. \& Lei, A. Electrocatalytic intramolecular oxidative annulation of $\mathrm{N}$-aryl enamines into substituted indoles mediated by iodides. Chem. Commun. 53, 3354-3356 (2017).

25. $\mathrm{Hu}, \mathrm{X}$. et al. Photoinduced oxidative activation of electron-rich arenes: alkenylation with $\mathrm{H}_{2}$ evolution under external oxidant-free conditions. Chem. Sci. 9, 1521-1526 (2018).

26. Ikeda, Y., Nakamura, T., Yorimitsu, H. \& Oshima, K. Cobalt-catalyzed Hecktype reaction of alkyl halides with styrenes. J. Am. Chem. Soc. 124, 6514-6515 (2002).

27. Firmansjah, L. \& Fu, G. C. Intramolecular Heck reactions of unactivated alkyl halides. J. Am. Chem. Soc. 129, 11340-11341 (2007).

28. Matsubara, R., Gutierrez, A. C. \& Jamison, T. F. Nickel-catalyzed Heck-type reactions of benzyl chlorides and simple olefins. J. Am. Chem. Soc. 133, 19020-19023 (2011).

29. Bloome, K. S., McMahen, R. L. \& Alexanian, E. J. Palladium-catalyzed Hecktype reactions of alkyl iodides. J. Am. Chem. Soc. 133, 20146-20148 (2011).

30. Weiss, M. E., Kreis, L. M., Lauber, A. \& Carreira, E. M. Cobalt-catalyzed coupling of alkyl iodides with alkenes: deprotonation of hydridocobalt enables turnover. Angew. Chem. Int. Ed. 50, 11125-11128 (2011).

31. Liu, C. et al. Nickel-catalyzed Heck-type alkenylation of secondary and tertiary a-carbonyl alkyl bromides. Angew. Chem. Int. Ed. 51, 3638-3641 (2012).

32. Nishikata, T., Noda, Y., Fujimoto, R. \& Sakashita, T. An efficient generation of a functionalized tertiary-alkyl radical for copper-catalyzed tertiary-alkylative Mizoroki-Heck type reaction. J. Am. Chem. Soc. 135, 16372-16375 (2013).

33. Tang, S., Liu, C. \& Lei, A. Nickel-catalysed novel $\beta, \gamma$-unsaturated nitrile synthesis. Chem. Commun. 49, 2442-2444 (2013).

34. Wang, J., Liu, C., Yuan, J. \& Lei, A. Copper-catalyzed oxidative coupling of alkenes with aldehydes: direct access to $\alpha, \beta$-unsaturated ketones. Angew. Chem. Int. Ed. 52, 2256-2259 (2013).

35. Zhu, Y. \& Wei, Y. copper catalyzed direct alkenylation of simple alkanes with styrenes. Chem. Sci. 5, 2379-2382 (2014)

36. Tang, S., Zeng, L., Liu, Y. \& Lei, A. Zinc-catalyzed dehydrogenative crosscoupling of terminal alkynes with aldehydes: access to ynones. Angew. Chem. Int. Ed. 54, 15850-15853 (2015).

37. Yuan, J. et al. Bimetallic zinc complex-active species in coupling of terminal alkynes with aldehydes via nucleophilic addition/Oppenauer oxidation. Chem. Commun. 51, 576-579 (2015).

38. Zou, Y. \& Zhou, J. Palladium-catalyzed intermolecular Heck reaction of alkyl halides. Chem. Commun. 50, 3725-3728 (2014). 
39. Ye, J. et al. Remote $\mathrm{C}-\mathrm{H}$ alkylation and $\mathrm{C}-\mathrm{C}$ bond cleavage enabled by an in situ generated palladacycle. Nat. Chem. 9, 361-368 (2016).

40. Wang, G.-Z., Shang, R., Cheng, W.-M. \& Fu, Y. Irradiation-induced Heck reaction of unactivated alkyl halides at room temperature. J. Am. Chem. Soc. 139, 18307-18312 (2017)

41. Kurandina, D., Parasram, M. \& Gevorgyan, V. Visible light-induced roomtemperature Heck reaction of functionalized alkyl halides with vinyl arenes/ heteroarenes. Angew. Chem. Int. Ed. 56, 14212-14216 (2017).

42. Zhou, H. et al. HOTf-catalyzed alkyl-Heck-type reaction. iScience 3, 255-263 (2018).

43. Ng, S.-S. \& Jamison, T. F. Simple alkenes as substitutes for organometallic reagents: nickel-catalyzed, intermolecular coupling of aldehydes, silyl triflates, and alpha olefins. J. Am. Chem. Soc. 127, 14194-14195 (2005).

44. Zhang, G. et al. External oxidant-free oxidative cross-coupling: a photoredox cobalt-catalyzed aromatic C-H thiolation for constructing C-S bonds. J. Am. Chem. Soc. 137, 9273-9280 (2015).

45. Wasa, M., Engle, K. M. \& Yu, J.-Q. Pd(II)-catalyzed olefination of $\mathrm{sp}^{3} \mathrm{C}-\mathrm{H}$ bonds. J. Am. Chem. Soc. 132, 3680-3681 (2010).

46. Stowers, K. J., Fortner, K. C. \& Sanford, M. S. Aerobic Pd-catalyzed sp ${ }^{3}$ C-H olefination: a route to both $N$-heterocyclic scaffolds and alkenes. J. Am. Chem. Soc. 133, 6541-6544 (2011).

47. Wang, H., Dai, X.-J. \& Li, C.-J. Aldehydes as alkyl carbanion equivalents for additions to carbonyl compounds. Nat. Chem. 9, 374-378 (2017).

48. Dai, X.-J., Wang, H. \& Li, C.-J. Carbonyls as latent alkyl carbanions for conjugate additions. Angew. Chem. Int. Ed. 56, 6302-6306 (2017).

49. Chen, N., Dai, X.-J., Wang, H. \& Li, C.-J. Umpolung addition of aldehydes to aryl imines. Angew. Chem. Int. Ed. 56, 6260-6263 (2017).

50. Wei, W. et al. Ruthenium(II)-catalyzed olefination via carbonyl reductive cross-coupling. Chem. Sci. 8, 8193-8197 (2017).

51. Li, C.-C. et al. Iron-catalyzed nucleophilic addition reaction of organic carbanion equivalents via hydrazones. Org. Lett. 20, 3801-3805 (2018).

52. Yan, S.-S. et al. Ruthenium-catalyzed umpolung carboxylation of hydrazones with $\mathrm{CO}_{2}$. Chem. Sci. 9, 4873-4878 (2018).

53. Tang, J. et al. Nickel-catalyzed cross-coupling of aldehydes with aryl halides via hydrazone intermediates. Chem. Commun. 54, 1750-1753 (2018).

54. Zhu, D. et al. Umpolung of carbonyl groups as alkyl organometallic reagent surrogates for palladium-catalyzed allylic alkylation. Angew. Chem. Int. Ed. 57, 16520-16524 (2018).

55. Lv, L., Qiu, Z., Li, J., Liu, M. \& Li, C.-J. $\mathrm{N}_{2} \mathrm{H}_{4}$ as traceless mediator for homoand cross- aryl coupling. Nat. Commun. 9, 4739 (2018).

56. Lv, L. et al. Cross-coupling of phenol derivatives with umpolung aldehydes catalyzed by nickel. ACS Catal. 8, 4622-4627 (2018).

57. Das, U. K., Chakraborty, S., Diskin-Posner, Y. \& Milstein, D. Direct conversion of alcohols into alkenes by dehydrogenative coupling with hydrazine/hydrazone catalyzed by manganese. Angew. Chem. Int. Ed. 57, 13444-13448 (2018).

58. Paquette, L. A. \& Lobben, P. C. $\pi$-Facial diastereoselection in the 1,2-addition of allylmetal reagents to 2-methoxycyclohexanone and tetrahydrofuranspiro(2-cyclohexanone). J. Am. Chem. Soc. 118, 1917-1930 (1996).

59. Xia, Y., Qiu, D. \& Wang, J. Transition-metal-catalyzed cross-couplings through carbene migratory insertion. Chem. Rev. 117, 13810-13889 (2017).

60. Barluenga, J. \& Valdés, C. Tosylhydrazones: new uses for classic reagents in palladium-catalyzed cross-coupling and metal-free reactions. Angew. Chem. Int. Ed. 50, 7486-7500 (2011).

61. Shao, Z. \& Zhang, H. N-Tosylhydrazones: versatile reagents for metalcatalyzed and metal-free cross-coupling reactions. Chem. Soc. Rev. 41, 560-572 (2012).
62. Xia, Y. \& Wang, J. N-Tosylhydrazones: versatile synthons in the construction of cyclic compounds. Chem. Soc. Rev. 46, 2306-2362 (2017).

63. Chen, F. et al. Remote migratory cross-electrophile coupling and olefin hydroarylation reactions enabled by in situ generation of NiH. J. Am. Chem. Soc. 139, 13929-13935 (2017).

64. Sommer, H., Juliá-Hernández, F., Martin, R. \& Marek, I. Walking metals for remote functionalization. ACS Cent. Sci. 4, 153-165 (2018).

65. Fagnou, K. \& Lautens, M. Halide effects in transition metal catalysis. Angew. Chem. Int. Ed. 41, 26-47 (2002).

\section{Acknowledgements}

We are grateful to the Canada Research Chair Foundation (to C.-J.L.), the Canadian Foundation for Innovation, FRQNT Centre in Green Chemistry and Catalysis, and the Natural Science and Engineering Research Council of Canada for support of our research. Dr. L.L. is grateful for the support from National Postdoctoral Program for Innovative Talents (No. BX201700110) and China Postdoctoral Science Foundation Funded Project (No. 2017M623270).

\section{Author contributions}

L.L. and D.Z. both performed the experiments and analyzed the data. C.-J.L. directed and conceived the project. L.L. wrote the paper with feedback and guidance from C.-J.L. All authors discussed the experimental results and commented on the manuscript.

\section{Additional information}

Supplementary Information accompanies this paper at https://doi.org/10.1038/s41467 019-08631-1.

Competing interests: The authors declare no competing interests.

Reprints and permission information is available online at http://npg.nature.com/ reprintsandpermissions/

Journal peer review information: Nature Communications thanks the anonymous reviewers for their contribution to the peer review of this work.

Publisher's note: Springer Nature remains neutral with regard to jurisdictional claims in published maps and institutional affiliations.

cc (i) Open Access This article is licensed under a Creative Commons Attribution 4.0 International License, which permits use, sharing adaptation, distribution and reproduction in any medium or format, as long as you give appropriate credit to the original author(s) and the source, provide a link to the Creative Commons license, and indicate if changes were made. The images or other third party material in this article are included in the article's Creative Commons license, unless indicated otherwise in a credit line to the material. If material is not included in the article's Creative Commons license and your intended use is not permitted by statutory regulation or exceeds the permitted use, you will need to obtain permission directly from the copyright holder. To view a copy of this license, visit http://creativecommons.org/ licenses/by/4.0/.

(c) The Author(s) 2019 